\title{
RADIOCARBON DATING OF WOOD USING DIFFERENT PRETREATMENT PROCEDURES: APPLICATION TO THE CHRONOLOGY OF ROTOEHU ASH, NEW ZEALAND
}

\author{
G M Santos ${ }^{1,2} \bullet \mathrm{M} \mathrm{I} \mathrm{Bird}^{3} \bullet$ B Pillans $^{3} \bullet \mathrm{L} \mathrm{K} \mathrm{Fifield}^{1} \bullet$ B V Alloway ${ }^{4} \bullet \mathrm{J} \mathrm{Chappell}^{3}$ \\ P A Hausladen ${ }^{1} \cdot$ A Arneth $^{5}$
}

\begin{abstract}
We compare radiocarbon accelerator mass spectrometry (AMS) ages of wood samples subjected to a conventional acid-base-acid pretreatment with stepped combustion (ABA-SC) with results from the same samples subjected to an acid-base-wet oxidation pretreatment with stepped combustion (ABOX-SC) and cellulose extraction with stepped combustion (CE-SC). The ABOX-SC procedure has been shown previously to lead to lower backgrounds for old charcoal samples. Analyses of relatively uncontaminated " $14 \mathrm{C}$-dead" samples of wood suggest that backgrounds of $0.11 \pm 0.04 \mathrm{pMC}$ are obtainable for both the ABOX-SC and ABA-SC procedures. Where wood is significantly contaminated the ABOX-SC technique provides significantly better decontamination than either the ABA-SC technique or cellulose extraction alone, although CE$\mathrm{SC}$ can produce comparably low backgrounds to the $\mathrm{ABOX}-\mathrm{SC}$ procedure.

We also report the application of the ABOX-SC, ABA-SC and CE-SC procedures to wood samples associated with the chronologically controversial Rotoehu Ash eruption, New Zealand. New ${ }^{14} \mathrm{C}$-AMS dates from wood sampled from below the Rotoehu Ash span an age range of 43-50 ka BP consistent with recently presented OSL dates of 42-44 ka obtained for palaeosols beneath the ash.
\end{abstract}

\section{INTRODUCTION}

It is well known that the range of radiocarbon dating is limited ultimately by contamination derived from small amounts of younger carbon. Detecting sample contamination and verifying the reliability of the measured ages becomes more problematic as sample age increases, and many laboratories prefer only to quote ${ }^{14} \mathrm{C}$ ages until $\sim 40 \mathrm{ka} \mathrm{BP}$. Ages greater than this limit are generally considered to be "infinite" as they not distinguishable from procedural blanks. The sensitivity of the ${ }^{14} \mathrm{C}$ method is, however, considerably better than this limit and both accelerator mass spectrometry (AMS) and radiometric laboratories could in principle reach ages of $60 \mathrm{ka}$ BP if sample contamination were reduced to sufficiently low levels.

A variety of sample pretreatments have been developed to try to remove younger contamination from samples and thus increase the age to which reliable ${ }^{14} \mathrm{C}$ dates can be obtained. For wood samples, pretreatments have included a combination of acid and base washes or the isolation of a particular fraction of the bulk wood sample such as cellulose (Loader et al. 1997). The acid-base-acid pretreatment is simple and rapid, but is not particularly selective, and does not always remove all contamination (Gillespie et al. 1992; Gillespie 1990, 1997). Cellulose extraction has the in-principle advantage of producing a single component, but the purity of the extract depends on the complexity of the extraction process employed. Green (1963) has defined some of these extracts, which in order of increasing purity are holocellulose, alpha-cellulose or cellulose itself. It has been shown (Head 1979; Chappell et al. 1996) that holocellulose can be strongly contaminated, and hence it is necessary to produce at least alpha-cellulose to minimize the contamination. The cellulose extraction process is, however, very time-consuming.

\footnotetext{
${ }^{1}$ Department of Nuclear Physics, Research School of Physical Sciences and Engineering, Australian National University, ACT 0200, Australia

${ }^{2}$ Corresponding author: E-mail: gss103@nuc.anu.edu.au.

${ }^{3}$ Research School of Earth Sciences, Australian National University, Canberra, ACT 0200, Australia

${ }^{4}$ Institute of Geological \& Nuclear Sciences, Private Bag 2000, Taupo, New Zealand

${ }^{5}$ Max Planck Institute for Biogeochemistry, Postfach 100164, 07701 Jena, Germany
}

(C) 2001 by the Arizona Board of Regents on behalf of the University of Arizona RADIOCARBON, Vol 43, Nr 2A, 2001, p 239-248

Proceedings of the 17 th International ${ }^{14} \mathrm{C}$ Conference, edited by I Carmi and E Boaretto 
The acid-base-wet oxidation pretreatment with stepped combustion (ABOX-SC) has been described by Bird et al. (1999). The technique has been shown to be capable of reliably removing contamination from charcoal, enabling credible ${ }^{14} \mathrm{C}$ dating of charcoal to $\sim 55 \mathrm{ka}$ BP. In this paper we test the suitability of a modified ABOX-SC procedure as a pretreatment for "old" wood samples. The ABOX-SC procedure can potentially provide a more rigorous pretreatment than simple combinations of acid-base washes, without the complicated procedures required for cellulose extraction.

The rationale for postulating that the ABOX-SC technique may be a useful pretreatment for wood is that the use of a wet oxidation step may oxidize labile contaminants not removed by simple acid-base washes. The $330^{\circ} \mathrm{C}$ combustion step, under oxygen flow, may also remove contaminants introduced during the pre-combustion sample loading procedure, while the $650^{\circ} \mathrm{C}$ combustion step without oxygen flow may remove further labile contamination as the wood samples undergo partial pyrolysis, thereby maximizing the chances that the $920^{\circ} \mathrm{C}$ combustion fraction will be free of contamination.

We first test the ABOX-SC and ABA-SC procedures using wood of known "infinite" age, and then apply both techniques to wood samples associated with the Rotoehu Ash in New Zealand. We also test these techniques against results obtained for alpha cellulose from the same samples (CE-SC).

The Rotoehu Ash is an important and widespread time-stratigraphic marker in New Zealand. The ash was produced in one of the largest eruptions during the Late Pleistocene from the Okaitana Volcanic Centre and its volume is estimated to be around $90 \mathrm{~km}^{3}$ (Froggatt and Lowe 1990). There have been several attempts to constrain the age of the Rotoehu Ash, with widely discrepant results. Conventional ${ }^{14} \mathrm{C}$ dates of 41.7 (NZ-1126) and $44 \mathrm{ka} \mathrm{BP}$ (NZ-877), along with several "infinite" ages initially suggested that the ash erupted close to the generally acknowledged limit of the ${ }^{14} \mathrm{C}$ technique (Froggatt and Lowe 1990; Lowe and Hogg 1995).

More recently, K/Ar dating of lava flows above and below the ash suggested an age of $64 \pm 4 \mathrm{ka}$ (Wilson et al. 1992), while uranium series (Ota et al. 1989) and electron-spin resonance (ESR) (Buhay et al. 1992) dating yielded ages of $71 \pm 6 \mathrm{ka}$ and $45 \pm 8 \mathrm{ka}$, respectively. Whitehead and Ditchburn (1994) have revised the interpretation of both the ESR and a wider body of ${ }^{14} \mathrm{C}$ data, and have suggested new values of $42.9 \pm 7.8 \mathrm{ka}$ and $35.1 \pm 2.8 \mathrm{ka}$ BP, respectively. They have also reported that the U/Th disequilibrium age is an overestimate and give four possible reasons why the original age of $71 \mathrm{ka}$ is likely to be incorrect, with the true age probably being much younger. However, Lowe and Hogg (1995) note that some of the ${ }^{14} \mathrm{C}$ data accepted by Whitehead and Ditchburn (1994) was likely to have come from samples contaminated by younger carbon.

In addition, indirect ages of $52 \mathrm{ka}$ and $55 \mathrm{ka}$ have been estimated from raised terrace chronologies (Berryman 1992) and marine sedimentation rates (Pillans and Wright 1992) respectively. According to Lian and Shane (2000) in their interpretation of these various dating studies (summarized in Table 1), it is safe to assume that Rotoehu Ash was erupted sometime between $35 \mathrm{ka}$ and $75 \mathrm{ka}$. They also performed OSL dating of palaeosols buried by Rotoehu Ash and their results suggested a maximum age of $42-44$ ka.

\section{SAMPLE COLLECTION AND LABORATORY PREPARATION}

The wood samples investigated in this study (listed in Tables 2 and 3, described below) were chosen to provide a reliable assessment of the total blank for the procedures used and to determine whether coherent geochronological information could be obtained on samples probably older than $40 \mathrm{ka}$.

Three natural wood samples, RWT, ANU-970 and ANU-918, were chosen as blanks, as their true ages have previously been reported to be in excess of $60 \mathrm{ka}$. Wood sample RWT was found $15 \mathrm{~km}$ 
Table 1 Comparison of ages available for the widespread Rotoehu Ash erupted in the Taupo Volcanic Zone, New Zealand and the ${ }^{14} \mathrm{C}$ age obtained in this study

\begin{tabular}{lcl}
\hline Dating methods & Age & References \\
\hline Conventional ${ }^{14} \mathrm{C}$ & $>40 \mathrm{ka}^{\mathrm{a}}$ & Froggat and Lowe (1990) \\
U/Th disequilibrium & $71 \pm 6 \mathrm{ka}$ & Ota et al. (1989) \\
Electron-spin Resonance (ESR) of quartz & $45 \pm 8 \mathrm{ka}$ & Buhay et al. (1992) \\
Stratigraphic position on raised marine terraces & $52 \pm 7 \mathrm{ka}^{\mathrm{b}}$ & Berryman (1992) \\
Sedimentation rates in a deep-sea core & $\sim 55 \mathrm{ka}^{\mathrm{b}}$ & Pillans and Wright (1992) \\
K-Ar ages on bracketing lavas & $64 \pm 4 \mathrm{ka}$ & Wilson et al. (1992) \\
OSL of palaeosols buried by the Rotoehu Ash & $42 \pm 8 \mathrm{ka}$ & Lian and Shane (2000) \\
& $44 \pm 3 \mathrm{ka}$ & \\
${ }^{14}$ C-AMS on wood from 4 cm below the Rotoehu Ash & $43.2 \pm 0.6 \mathrm{ka}^{\mathrm{a}}$ & This study \\
\hline${ }^{\mathrm{a}{ }^{14} \mathrm{C} \text { ages }}$ & & \\
${ }^{\mathrm{b}}$ Ages estimated & &
\end{tabular}

inland from the present coastline west of Wanganui, North Island, New Zealand, beneath a mid Pleistocene volcanic ash layer (Rangitawa Tephra), that was erupted from the Taupo Volcanic Zone (Figure 1). This tephra has been dated at $345 \pm 12$ ka based on eleven zircon (Kohn et al. 1992) and isothermal plateau (Alloway et al. 1993; Pillans et al. 1996) fission track age determinations. The wood samples ANU-970 and ANU-918 have previously been dated by liquid scintillation counting at the Australian National University Radiocarbon Dating Laboratory and have given results of "background" and $35.2 \mathrm{ka} \mathrm{BP}$, respectively (Chappell et al. 1996). Both of these samples are from kauri logs preserved in coastal siliceous sand barriers in northern New South Wales, Australia. These barriers were formed at ages ranging between $120-130 \mathrm{ka}$, as determined by ${ }^{230} \mathrm{Th} /{ }^{234} \mathrm{U}$ dates of corals associated with the same barrier formations (Marshall and Thom 1976).

For the Rotoehu Ash chronology investigation, two wood samples were taken from peat layers immediately above and below an outcrop of the ash deposit on North Kaipara Barrier. These samples are labelled "Above Rotoehu Ash" (ARA) and "4 cm Below Rotoehu Ash" (4BRA). The North Kaipara Barrier has an average width of $7 \mathrm{~km}$ and stretches $85 \mathrm{~km}$ southeast from Manganui Bluff to the Kaipara North Head, in North Island, New Zealand (Figure 1). Pollen studies show that the Barrier was covered with a mature kauri-podocarp-hardwood forest prior to the eruption of the Rotoehu Ash (Murray and Grant-Mackie 1989). The wood samples were preserved in highly carbonaceous muds. The Rotoehu Ash was identified by geochemical fingerprinting of glass shards using electron microprobe analyses (BV Alloway, unpublished data). In addition to the two samples above, another sample from below the ash was also available, but the precise depth of this sample below the ash layer was not recorded. In the following, this sample is labelled "Below Rotoehu Ash" (BRA).

Samples were stored in plastic bags and were later handled individually in a clean lab. All pretreatment steps are carried out in a laminar flow cabinet or fume hood. The vessels and implements used during the combustion and graphitization process were rigorously pre-cleaned using the protocol described by Bird et al. (1999). The surfaces of the whole wood samples were removed mechanically before the wood was shaved in to small fragments and 800-1000 mg aliquots were weighed and sub-divided into two $50 \mathrm{~mL}$ capped plastic Falcon ${ }^{\circledR}$ centrifuge tubes. Both tubes were filled with $20 \mathrm{~mL}$ of $6 \mathrm{M} \mathrm{HCl}$ solution. The samples were left to stand in this solution for at least one hour, after which they were centrifuged and rinsed twice with Milli- $\mathrm{Q}^{\circledR}$ water. Fifty milliliters of $1 \mathrm{M} \mathrm{NaOH}$ were then added to each tube, which were left to stand overnight (approximately $10 \mathrm{hr}$ ) before rinsing twice with Milli- ${ }^{\circledR}{ }^{\circledR}$ water. These steps were carried out to remove acid and base soluble organic material, respectively. 
Table 2 New pMC and ${ }^{14} \mathrm{C}$-AMS ages for blank experiments on " ${ }^{14} \mathrm{C}$-dead" samples from wood measured in this study, prepared using the ABA-SC, ABOX-SC and CE-SC procedures. A $\delta^{13} \mathrm{C}$ value of $-25 \%$ was assumed.

\begin{tabular}{|c|c|c|c|c|c|c|c|c|c|}
\hline Sample & Description & Pretreatment & $\begin{array}{c}\text { Fraction } \\
\left({ }^{\circ} \mathrm{C}\right)\end{array}$ & ANUA $^{\mathrm{a}}$ & $\begin{array}{l}\mathrm{CT}^{\mathrm{b}} \\
\text { (h) }\end{array}$ & $\mathrm{pMC}$ & $\begin{array}{l}\text { Error } \\
(1 \sigma)\end{array}$ & $\begin{array}{c}{ }^{14} \mathrm{C} \text { age } \\
(\mathrm{BP})\end{array}$ & $\begin{array}{l}\text { Uncertainty } \\
\qquad(1 \sigma)\end{array}$ \\
\hline \multirow[t]{5}{*}{ ANU-970 } & $\begin{array}{l}\text { Sample of Kauri log preserved in } \\
\text { coastal sand barriers in northern } \\
\text { New South Wales, Australia }\end{array}$ & Holocellulose & & & & & & Background $^{\mathrm{d}}$ & \\
\hline & & ABA-SC & 910 & 14116 & 10 & 0.113 & 0.013 & 54,410 & $+970 /-860$ \\
\hline & & ABOX-SC & 910 & 14109 & 10 & 0.107 & 0.013 & 54,800 & $+1010 /-900$ \\
\hline & & & 650 & 14110 & 1 & 0.113 & 0.019 & 54,420 & $+1470 /-1240$ \\
\hline & & CE-SC & 910 & 15514 & 10 & 0.209 & 0.034 & 49,450 & $+1440 /-1220$ \\
\hline \multirow[t]{2}{*}{ RWT } & Sample from below Rangitawa & & 920 & 14107 & 10 & 0.097 & 0.011 & 55,630 & $+1025 /-910$ \\
\hline & Tephra, New Zealand & ABA-SC & 650 & 14108 & 1 & 0.202 & 0.043 & 49,740 & $+1920 /-1550$ \\
\hline \multirow[t]{8}{*}{ ANU-918 } & $\begin{array}{l}\text { Sample of Kauri log preserved in } \\
\text { coastal sand barriers in northern }\end{array}$ & & & & & & & & \\
\hline & New South Wales, Australia & Untreated wood & & & & & & $23,290^{d}$ & 560 \\
\hline & & Resin & & & & & & $11,100^{\mathrm{d}}$ & 880 \\
\hline & & Humic and fulvic & & & & & & $15,900^{\mathrm{d}}$ & 180 \\
\hline & & Holocellulose & & & & & & $35,200^{\mathrm{d}}$ & $+2000 /-1500$ \\
\hline & & ABA-SC & 910 & 14118 & 10 & 0.557 & 0.042 & 41,580 & $+620 /-580$ \\
\hline & & ABOX-SC & 910 & 14114 & 10 & 0.251 & 0.051 & 48,000 & $+1830 /-1490$ \\
\hline & & CE-SC & 910 & 15513 & 10 & 0.147 & 0.026 & 52,290 & $+1560 /-1310$ \\
\hline
\end{tabular}

${ }^{\mathrm{a} C o d e}$ number of ANU-AMS measurements

${ }^{\mathrm{b}} \mathrm{CT}=$ combustion time.

${ }^{\mathrm{c}}$ The $\delta^{13} \mathrm{C}$ values have not been measured but were assumed to be $-25 \%$. The carbon-isotope composition of the ANU sucrose standard is $-11 \%$, and a fraction correction of $14 \%$ o (110 yr) has been applied to each of the wood samples

${ }^{\mathrm{d} 14} \mathrm{C}$ dates of wood and wood extracts from last interglacial (samples submitted by B G Thom. The results were published in Chappell et al. [1996]). Kauri wood of ANU 918 is from a strongly humified sand deposit. Conventionally dated fractions had the following pretreatments: ethanol-ethyl acetate-acetone ("resin"); followed by NaOH (soluble = "humic"), followed by $\mathrm{NaClO}_{2}$ (holocellulose) (Head 1979). 
Table 3 New pMC and ${ }^{14} \mathrm{C}$-AMS ages for wood samples associated to a Rotoehu Ash eruption, prepared using the ABA-SC, ABOX-SC, and CE-SC procedures. A $\delta^{13} \mathrm{C}$ value of $-25 \%$ was assumed.

\begin{tabular}{|c|c|c|c|c|c|c|c|c|c|}
\hline Sample & Description & Pretreatment & $\begin{array}{l}\text { Fraction } \\
\left({ }^{\circ} \mathrm{C}\right)\end{array}$ & ANUA $^{\mathrm{a}}$ & $\begin{array}{l}\mathrm{CT}^{\mathrm{b}} \\
(\mathrm{h})\end{array}$ & $\mathrm{pMC}^{\mathrm{c}}$ & $\begin{array}{l}\text { Error } \\
(1 \sigma)\end{array}$ & $\begin{array}{c}{ }^{14} \mathrm{C}_{\text {age }}^{\mathrm{d}} \\
(\mathrm{yr})\end{array}$ & $\begin{array}{l}\text { Uncertainty } \\
\qquad(1 \sigma)\end{array}$ \\
\hline \multirow[t]{4}{*}{ ARA } & \multirow[t]{4}{*}{ Above Rotoehu Ash } & \multirow[t]{2}{*}{$\mathrm{ABA}-\mathrm{SC}$} & 920 & 13018 & 1 & 8.748 & 0.352 & 19,460 & $+330 /-310$ \\
\hline & & & 650 & 13019 & 1 & 9.189 & 0.244 & 19,070 & $+210 /-210$ \\
\hline & & \multirow[t]{2}{*}{$\mathrm{AOX}-\mathrm{SC}^{\mathrm{e}}$} & 920 & 13016 & 1 & 9.227 & 0.232 & 19,030 & $+200 /-200$ \\
\hline & & & 650 & 13017 & 1 & 9.299 & 0.231 & 18,970 & $+200 /-190$ \\
\hline \multirow[t]{3}{*}{ 4BRA } & \multirow[t]{3}{*}{$4 \mathrm{~cm}$ below Rotoehu Ash } & \multirow[t]{2}{*}{ ABA-SC } & 910 & 14103 & 10 & 0.471 & 0.051 & 42,930 & $+740 /-680$ \\
\hline & & & 650 & 14104 & 1 & 0.476 & 0.050 & 42,840 & $+720 /-660$ \\
\hline & & ABOX-SC & 910 & 15518 & 10 & 0.423 & 0.053 & 43,800 & $+840 /-760$ \\
\hline \multirow[t]{7}{*}{ BRA } & \multirow[t]{7}{*}{ Below Rotoehu Ash } & \multirow[t]{2}{*}{$\mathrm{ABA}-\mathrm{SC}$} & 910 & 14105 & 10 & 0.261 & 0.041 & 47,690 & $+950 /-850$ \\
\hline & & & 650 & 14106 & 1 & 0.266 & 0.041 & 47,530 & $+940 /-840$ \\
\hline & & \multirow{2}{*}{$\mathrm{AOX}-\mathrm{SC}^{\mathrm{e}}$} & 920 & 13013 & 10 & 0.349 & 0.073 & 45,330 & $+1410 /-1200$ \\
\hline & & & 650 & 13014 & 1 & 0.290 & 0.052 & 46,820 & +1140/-990 \\
\hline & & \multirow[t]{2}{*}{ ABOX-SC } & 910 & 13502 & 10 & 0.183 & 0.041 & 50,520 & $+1240 /-1070$ \\
\hline & & & 650 & 13504 & 1 & 0.334 & 0.049 & 45,700 & $+950 /-850$ \\
\hline & & CE-SC & 910 & 15516 & 10 & 0.200 & 0.043 & 49,820 & $+1210 /-1050$ \\
\hline
\end{tabular}

${ }^{\mathrm{a}}$ Code number of ANU-AMS measurements

${ }^{\mathrm{b}} \mathrm{CT}=$ combustion time.

${ }^{\mathrm{c}} \mathrm{A}$ correction of $0.11 \pm 0.04(1 \sigma)$ has been subtracted from the measured pMC for each sample. This value represents the background of the pretreatment procedure and AMS measurements.

${ }^{\mathrm{d}}$ The $\delta^{13} \mathrm{C}$ values have not been measured but were assumed to be $-25 \%$. The carbon-isotope composition of the ANU sucrose standard is $-11 \%$, and a fraction correction of $14 \%$ o (110 yr) has been applied to each of the wood samples.

${ }^{\mathrm{e}}$ These samples were not subjected to alkaline solution extraction. 


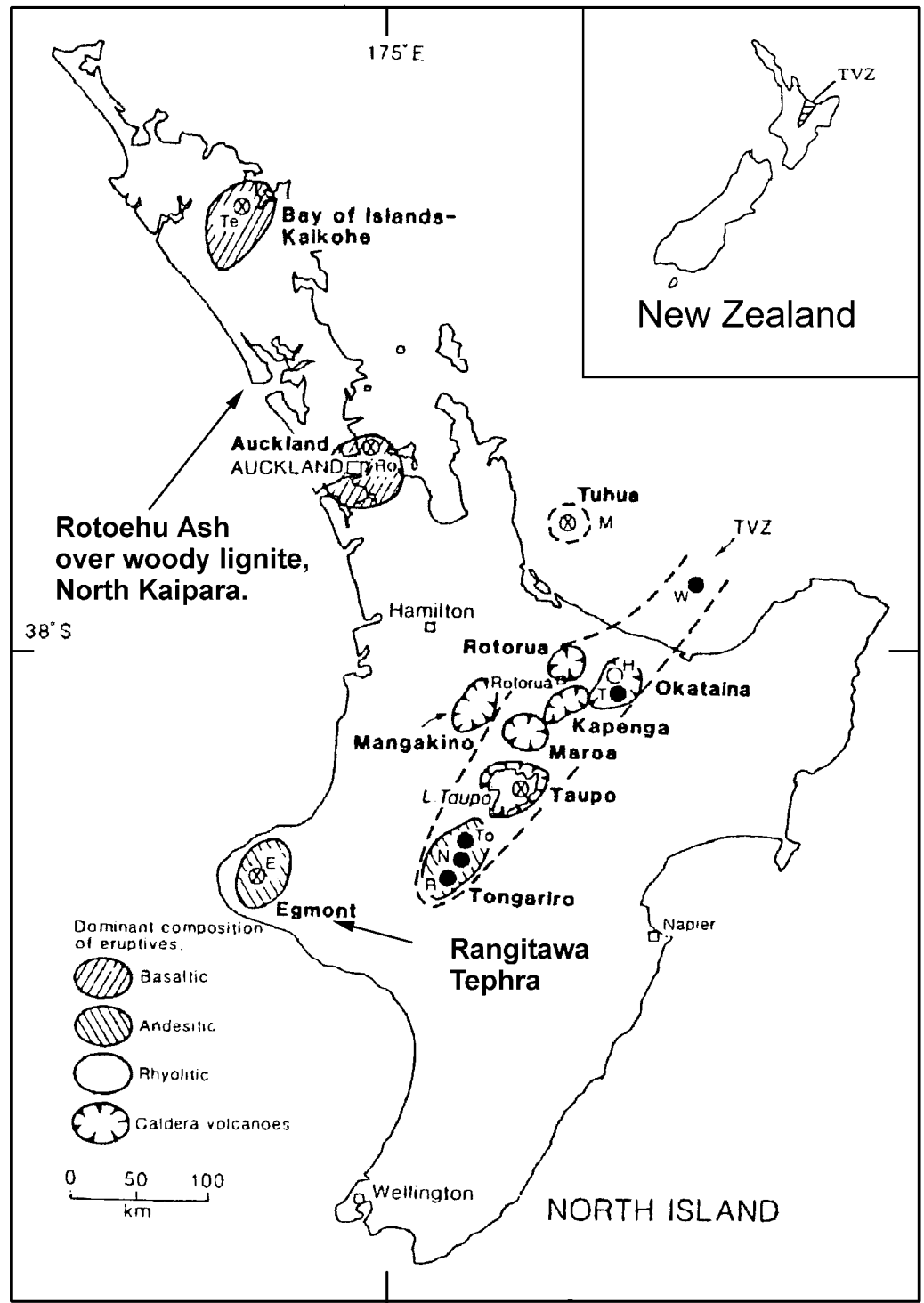

Figure 1 Map showing the distribution of volcanic centers or districts (bold names) in the North Island, New Zealand as well as the locations of the New Zealand wood samples studied in the present work (adapted from Lowe 1990)

One tube was then selected to undergo the final step of acid/base/acid (ABA) pretreatment. It was filled with a fresh $20 \mathrm{~mL}$ of $6 \mathrm{M} \mathrm{HCl}$ solution and left to stand for at least 3 hours at room temperature, after which the supernatant was discarded and the remaining fragments of wood were washed twice with warm Milli- $\mathrm{Q}^{\circledR}$ water. Finally the clean sample was covered and allowed to dry in a warm oven $\left(80^{\circ} \mathrm{C}\right)$.

The second sub-sample underwent the wet oxidation step that corresponds to the final step of the ABOX pretreatment. Thirty milliliters of acid-dichromate oxidant solution $\left(0.1 \mathrm{M} \mathrm{K}_{2} \mathrm{Cr}_{2} \mathrm{O}_{7}\right.$ in $2 \mathrm{M}$ solution of $\mathrm{H}_{2} \mathrm{SO}_{4}$ ) was added to the tube, which was capped and heated to $60.5^{\circ} \mathrm{C}$ in a temperature- 
regulated hot box. With the exceptions of the ANU-918 and RWT samples, which stood in this solution for only 1 hour and 21 hours, respectively, the samples were centrifuged after 5-6 hours. This dichromate solution acts very aggressively on some samples, and temperature and time were the compromise required to ensure that sufficient sample material was left for further analysis. Again, the supernatant was discarded, the remaining fragments of wood were washed twice with warm Milli-Q ${ }^{\circledR}$ water, covered and allowed to dry in a warm oven.

Some aliquots of natural wood samples underwent only an acid-wet oxidation stepped combustion (AOX-SC), i.e. the alkaline solution was left out of the procedure. This treatment was employed to determine the relative importance of the base step in removing contamination.

For the cellulose-extraction stepped-combustion (CE-SC) investigations, aliquots of the same set of natural wood samples were sent to the Max Planck Institute for Biogeochemistry, Germany to undergo the standard alpha cellulose extraction procedure as described by Loader et al. (1997).

The combustion and graphitization procedures were carried out as described by Bird et al. (1999), with the exception that the combustion time of the last step $\left(910{ }^{\circ} \mathrm{C}\right.$ or $\left.920{ }^{\circ} \mathrm{C}\right)$ was increased from 1 hour to at least 10 hours. The time was increased in an effort to ensure the complete reaction of other contaminant gases with the silver wire in the combustion tube, as it was suspected that the iron powder catalyst was being poisoned by some unremoved product at the shorter combustion time. Many fewer failures have been recorded since the combustion time was increased. Graphite targets were made from $\mathrm{CO}_{2}$ produced at each of the two higher temperature combustion steps (i.e. $650{ }^{\circ} \mathrm{C}$ and $910{ }^{\circ} \mathrm{C} / 920^{\circ} \mathrm{C}$ ) as shown in Tables 2 and 3, but the $\mathrm{CO}_{2}$ evolved at $330{ }^{\circ} \mathrm{C}$ was discarded. Bird et al. (1999) showed that the $330^{\circ} \mathrm{C}$ fraction generally contained some contamination, and its routine measurement is therefore considered unnecessary.

\section{RADIOCARBON ACCELERATOR MASS SPECTROMETRY ANALYSIS}

The graphite-plus-iron powder targets were pressed into $1 \mathrm{~mm}$ diameter holes in copper sample holders and loaded into a 32-sample wheel of an NEC multi-sample negative ion source. Ratios of ${ }^{14} \mathrm{C} /$ ${ }^{13} \mathrm{C}$ were measured by AMS using the 14UD accelerator at the Australian National University (ANU). Complete results are shown in Tables 2 and 3. The reproducibility of the ANU system for ${ }^{14} \mathrm{C}$ is approximately $1.5 \%$. All ages listed in Tables 2 and 3 are conventional ${ }^{14} \mathrm{C}$ ages. The $\delta^{13} \mathrm{C}$ values were not measured but have been assumed to be $-25 \%$ for the wood samples. The source of the error is statistical and the time of the measurement was the same for all samples. However, some of the graphite targets were very small and provided low current beams, which resulted in larger statistical errors for those samples.

\section{RESULTS AND DISCUSSION}

\section{Blanks}

The procedural blank was deduced from the results for the RWT and ANU-970 samples. Apparent ages for these two samples from the $910^{\circ} \mathrm{C} / 920^{\circ} \mathrm{C}$ combustion fraction cluster tightly around $55 \mathrm{ka} \mathrm{BP}$ and are independent of the pretreatment procedure, ABA or ABOX. For the celluloseextraction stepped-combustion (CE-SC) procedure, the ANU-970 blank is slightly younger than for the $\mathrm{ABA}$ or $\mathrm{ABOX}$ procedures.

For ANU-970, the two temperature fractions of the ABOX-treated sample give equivalent results, but for the ABA-treated RWT sample, the higher temperature fraction is clearly superior. Unfortunately, the $\mathrm{CO}_{2}$ evolved from the ABA-treated ANU-970 sample at $650{ }^{\circ} \mathrm{C}$ and from the ABOX- 
treated RWT sample at both $650{ }^{\circ} \mathrm{C}$ and $920^{\circ} \mathrm{C}$ failed to graphitize. We suspect that the reason for this is production of volatile sulfur compounds stemming from the use of sulfuric acid in the last step of ABOX chemical pretreatment. In addition, pyrolysis yields volatile organic components that may be trapped by liquid nitrogen and may cause difficulties in graphitization. We also investigated the nature and structure of RWT sample, which proved to be not pure wood, but a mixture of strongly compressed wood and mud.

The combined results from the $920^{\circ} \mathrm{C}$ fractions of these two samples indicate that the procedural blank is $0.11 \pm 0.04 \mathrm{pMC}$ for both the ABOX-SC and ABA-SC techniques for relatively uncontaminated wood samples. This blank has been subtracted from the Rotoehu Ash samples in Table 3.

\section{Relative Efficacy of ABA-SC, ABOX-SC and CE-SC Procedures for Contaminated Wood}

The ANU-918 sample represents an ideal sample with which to compare the relative efficacy of the $\mathrm{ABOX}$ and the ABA pretreatments, as previous work has suggested that it is significantly contaminated. An age for the bulk untreated wood of $23.3 \mathrm{ka}$ BP had been obtained by liquid scintillation counting, and ages as young as $11.1 \mathrm{ka}$ BP had been obtained for specific chemical fractions (Table 2; see also Head 1979 and Chappell et al. 1996). This sample was from a Kauri stump within humic-rich dark brown sand. The results of the present work show that both the ABOX-SC and CESC procedures were able to remove almost all of the contamination from this heavily-contaminated sample. For the cellulose sample, the high-temperature fraction is indistinguishable from the blank. The value of $0.25 \pm 0.05 \mathrm{pMC}$ obtained from the $920{ }^{\circ} \mathrm{C}$ fraction of the ABOX-treated sample, although statistically distinguishable from $0.11 \pm 0.04 \mathrm{pMC}$ of the blank, nevertheless indicates that any remaining contamination is $\sim 0.15 \mathrm{pMC}$ or less. In contrast, the results from the ABA-SC procedure indicate a higher residual contamination of $\sim 0.45 \mathrm{pMC}$ for the same combustion fraction $\left(910^{\circ} \mathrm{C}\right)$, demonstrating that the ABA-SC procedure was less effective at removing contamination than either the ABOX-SC or CE-SC procedures.

\section{Dating the Rotoehu Ash}

For the wood sample collected from above the Rotoehu Ash (ARA) the results of the ABA-SC and AOX-SC procedures for both higher-temperature fractions were not significantly different and the mean age was $19.0 \pm 0.2 \mathrm{ka} \mathrm{BP}$ (Table 3). This suggests that no peat accumulated over the ash layer at this location for several thousands of years, and therefore provides only a very loose constraint on the minimum age of the tephra.

A maximum age for the tephra is provided by the 4BRA sample, which was collected from $4 \mathrm{~cm}$ below the ash layer. All three measurements on this sample are in good agreement (Table 3). Although the high-temperature ABOX result is marginally older than the two ABA results, the close agreement between the two temperature fractions of the latter argues against significant residual contamination, and the average of the three results, $43.2 \pm 0.5 \mathrm{ka} \mathrm{BP}$, is taken as the best estimate of the ${ }^{14} \mathrm{C}$ age of this sample. Calibration of the ${ }^{14} \mathrm{C}$ time scale in this age range is problematic, but the calibrated age is likely to be at least $46 \mathrm{ka}$. This date, which represents a maximum age for the tephra as four centimeters of peat accumulated after the deposition of the wood sample and before the eruption of the tephra, is consistent with the recently reported OSL age of 42-44 ka for palaeosols beneath the Rotoehu Tephra (Lian and Shane 2000).

The results for the BRA sample, which was also collected from below the tephra but from an unrecorded position, shed further light on the effects of pretreatment on apparent sample age. The oldest age of $50.5 \mathrm{ka} \mathrm{BP}$ for this sample has been obtained from the ABOX-SC pretreated $910{ }^{\circ} \mathrm{C}$ fraction, 
although this is statistically indistinguishable from the high-temperature fraction from the alpha cellulose extraction. Variably younger ages down to $45.3 \mathrm{ka} \mathrm{BP}$ were obtained for the other pretreatments and lower-temperature combustion steps. In particular, the AOX procedure, in which the alkaline step is omitted, yields the youngest ages, demonstrating that the full ABOX-SC procedure is required for reliable results.

\section{CONCLUSIONS}

The ABOX pretreatment combined with a stepped combustion procedure, using the new vacuum line described in Bird et al. (1999), has produced reliable backgrounds equivalent to $~ 54 \mathrm{ka} \mathrm{BP}$ for known "infinitely" old wood. It also appears that the technique is better able to remove contamination than the more conventional ABA pretreatment, even when the latter is combined with stepped combustion. Further, it appears to be equivalent to the more complex procedure of alpha cellulose extraction, provided that the cellulose is also subjected to stepped combustion.

The results further suggest that the entire $\mathrm{ABOX}-\mathrm{SC}$ procedure is required to effect decontamination to the greatest degree possible, as eliminating the base wash from the procedure demonstrably reduces the efficiency of decontamination. The technique can be reliably used to date wood up to $\sim 50 \mathrm{ka} \mathrm{BP}$, as has been previously shown for charcoal. The technique holds promise for providing a rapid alternative to the laborious process of cellulose extraction for many samples.

New ${ }^{14} \mathrm{C}$-AMS data for wood sampled from below the Rotoehu Ash imply that the Rotoehu Ash was deposited after $43.2 \mathrm{ka} \mathrm{BP}$, a conclusion that is consistent with the recently presented OSL dates of 42-44 ka (Lian and Shane 2000). The ${ }^{14} \mathrm{C}$-AMS results are significantly younger than the currently accepted age of the tephra from K/Ar dating of $64 \pm 4 \mathrm{ka}$ (Wilson et al. 1992). It was not possible to constrain accurately a minimum age for deposition of the ash, as it would appear that peat did not start to accumulate over the ash until $\sim 19 \mathrm{ka}$ BP.

\section{ACKNOWLEDGMENTS}

GMS acknowledges the provision of a fellowship from the Conselho Nacional de Desenvolvimento Científico e Tecnológico (CNPq). BP and BVA acknowledge the financial support of the Marsden Fund, Royal Society of New Zealand (96-UOA-ESA-0010).

\section{REFERENCES}

Alloway BV, Pillans BJ, Sandhu AS, Westgate JA. 1993. Revision of the marine chronology in Wanganui Basin, New Zealand, based on the isothermal plateau fission-track dating of tephra horizons. Sedimentary Geology 82:299-310.

Berryman KR. 1992. A stratigraphic age of Rotoehu Ash and Late Pleistocene climate interpretation based on marine terrace chronology, Mahia Peninsula, North Island, New Zealand. New Zealand Journal of Geology and Geophysics 35:1-7.

Bird MI, Ayliffe LK, Fifield LK, Turney CSM, Cresswell RG, Barrows TT, David B. 1999. Radiocarbon dating of "old" charcoal using a wet oxidation-stepped combustion procedure. Radiocarbon 41(2):127-40.

Buhay WM, Clifford PM, Schwarcz HP. 1992. ESR dating of the Rotoiti Breccia in the Taupo Volcanic Zone, New Zealand. Quaternary Science Reviews 11:267-71.
Chappell J, Head J, Magee J. 1996. Beyond the radiocarbon limit in Australian archaeology and Quaternary research. Antiquity 70:543-52.

Froggatt PC, Lowe DJ. 1990. A review of late Quaternary silic and some other tephra formations from New Zealand: their stratigraphy, nomeclature, distribution, volume, and age. New Zealand Journal of Geology and Geophysics 33:89-109.

Gillespie R, Hammond AP, Goh KM, Tonkin PJ, Lowe DC, Sparks RJ, Wallace G. 1992. AMS radiocarbon dating of a late quaternary tephra site at Graham's Terrace, New Zealand. Radiocarbon 34(1):21-8.

Gillespie R. 1990. On the use of oxidation for AMS sample pretreatment. Nuclear Instruments and Methods in Physics Research B52:345.

Gillespie R. 1997. Burnt and unburnt carbon: dating charcoal and burnt bone from the Willandra Lakes, 
Australia. Radiocarbon 39(3):225-36.

Green JW. 1963. Wood cellulose. In: Methods in Carbohydrate Chemistry. Volume 3. Whisttler RL, editor. New York and London: Academic Press. p 9-23.

Head MJ. 1979. Structure and properties of fresh and degraded wood: their effects on radiocarbon activity measurements [unpublished MSc thesis]. Australian National University, Canberra.

Kohn BP, Pillans B, McGlone MS. 1992. Zircon fission track age for middle Pleistocene Rangitawa Tephra, New Zealand: stratigraphic and paleoclimatic significance. Palaeogeography, Palaeoclimatology, Palaeoecology 95:73-94.

Lian OB, Shane PA. 2000. Optical dating of paleosols bracketing the widespread Rotoehu tephra, North Island, New Zealand. Quaternary Science Reviews 19: 1649-662.

Loader NJ, Robertson I, Barker AC, Switsur VR, Waterhouse JS. 1997. An improved technique for the bach processing of small wholewood samples to a-cellulose. Chemical Geology 136(3-4):313-7.

Lowe DJ. 1990 Tephra studies in New Zealand: a historical review. Journal of the Royal Society of New Zealand 20:119-50.

Lowe DJ, Hogg AG. 1995. Age of Rotoehu Ash - comment. New Zealand Journal of Geology and Geophysics 38:399-402.

Marshall JF, Thom BG. 1976. The sea-level in the Last
Interglacial. Nature 263:120-21.

Murray DF, Grant-Mackie JA. 1989. Lower Pleistocene pollen profile, Rotuna Formation, North Kaipara Barrier, New Zealand. In: Spörli B, Kear D, editors. Geology of Northland, The Royal Society of New Zealand Bulletin 26:225-35.

Ota Y, Omura A, Iwata H. 1989. ${ }^{230} \mathrm{Th}-{ }^{238} \mathrm{U}$ age of Rotoehu Ash and its implications for marine terrace chronology of eastern Bay Plenty, New Zealand. New Zealand Journal of Geology and Geophysics 32:327-31.

Pillans B, Wright I. 1992. Late Quaternary tephrostratigraphy from the southern Harver Trough-bay of Plenty, Northeast New Zealand. New Zealand Journal of Geology and Geophysics 35:129-43.

Pillans B, Froggatt P, Kohn BP, Berger G, Walter RC, Duller G, Alloway BV, Hesse P. 1996. Multi-method dating comparison for mid-Pleistocene Rangitawa Tephra, New Zealand. Quaternary Science Reviews (Quaternary Geochronology) 15:641-53.

Wilson CJN, Hought BF, Laphere MA, Weaver SD. 1992. A new radiometric age estimate for the Rotoehu Ash from Mayor Island volcano, New Zealand. New Zealand Journal of Geology and Geophysics 35:371-4.

Whitehead N, Ditchburn R. 1994. Revision of some ages for the Rotoehu Ash. New Zealand Journal of Geology and Geophysics 37:381-3. 